\title{
Angelo Mazzotti: All Sides to an Oval: Properties, Parameters, and Borromini's Mysterious Construction
}

\section{Springer, 2017}

\author{
Ana López-Mozo ${ }^{1}$ (D)
}

Published online: 7 December 2017

(C) Kim Williams Books, Turin 2017

Angelo Mazzotti's All Sides to an Oval addresses a fundamental subject for architects, civil engineers and mathematicians involved in designing oval forms or analysing existing ones. The book contains a comprehensive collection of geometrical constructions and mathematical equations on the properties of ovals, the main parameters for managing them, and two case studies of actual built oval forms. In addition, the author poses some new geometrical constructions. A book of this kind on this subject was necessary since only some partial expositions have been previously published. All sections are illustrated with clear drawings that permit an easy understanding. Mazzotti's training in mathematics and geometry gives him the best skills to carry out this work.

The book first tackles the geometrical properties of simple ovals of four centres the most common ones- providing the reader with the tools needed to design an oval form that satisfy given conditions. These tools are not currently provided by CAD programs. The need to inscribe or circumscribe ovals in a given rectangle is a key problem to be solved by architects and designers in any project at any time. Mazzotti provides the tools to manage the situation even when a set of concentric ovals must be drawn into two non-equidistant rectangles, as it happens in stadiums. All given constraints situations are analysed, as are the ways to measure area and perimeter and the opportunities to optimize the oval form.

The way to draw an oval into a given rectangle was a problem solved for the first time by Abraham Bosse (1604-1676) in 1655. Before that moment, ovals of this type were likely drawn by trial and error. If proportions were not previously fixed, before Bosse there were known constructions giving ovals with determined proportions. This issue was especially carried out by architects of the Renaissance

Ana López-Mozo

ana.lopez.mozo@upm.es

1 School of Architecture, Polytechnic University of Madrid, Av. Juan de Herrera 4, 28040 Madrid, Spain 
such as the Italians Sebastiano Serlio (1475-c.1554) and Jacopo Barozzi da Vignola (1507-1573) or the Spaniards Alonso de Vandelvira (1544-1626), Hernán Ruiz (1514-1569) and later Fray Lorenzo de San Nicolás (1593-1679) and Joseph Gelabert (1621-1668). All these constructions and the ones posed by recent authors, some of them accomplishing given conditions, are analysed by Mazzotti.

Finally, the book presents two case studies of actual built oval forms. On the basis of rigorous surveys provided by the University of La Sapienza in Rome, the geometry underlying the oval forms of San Carlo alle Quattro Fontane by Borromini and the Coliseum in Rome are analysed by Mazzotti. In both cases the author approaches the initial project that was carried out and which parameters were taken into account. One of the most interesting conclusions is that Borromini might have known the method by Bosse (1655) when designing the oval dome at San Carlo alle Quattro Fontane (ca. 1660).

As it has been explained, Angelo Mazzotti's All Sides to an Oval is a fundamental book for anyone working with oval forms from the point of view of the geometric control of the shapes.

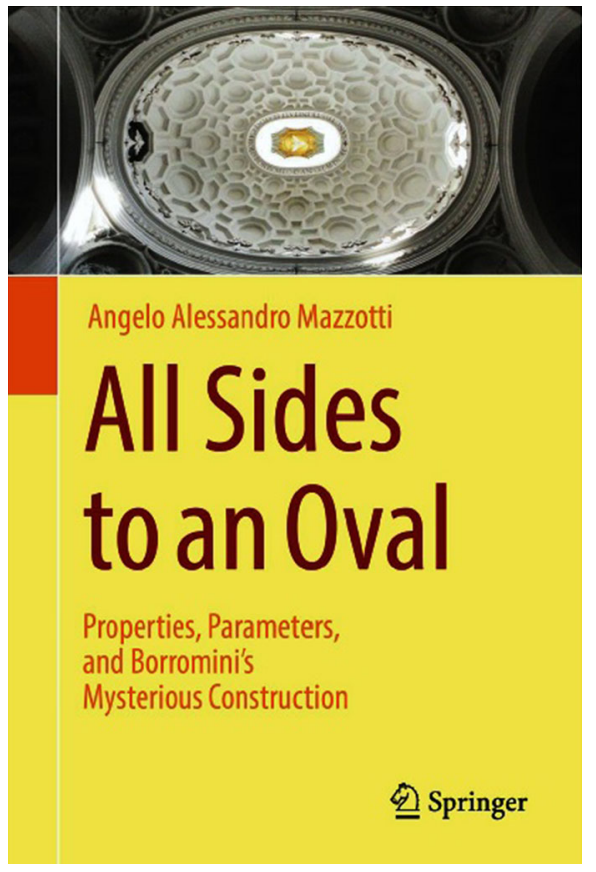

Ana López-Mozo is a doctor architect. She is Professor of Geometry, Architectural Drawing and Stonecutting at the School of Architecture of the Polytechnic University of Madrid. She also lectures in graduate courses on construction and technology of historical buildings. Her research focuses on stereotomy, arches, vaults and domes and has appeared in international conference proceedings, journals and books. She is now co-leading a research project on technical knowledge transfer in European late Gothic architecture, funded by the Spanish Ministry of Economy and Competitiveness. 